\title{
1 Historic collections as a tool for assessing the global pollinator
}

2 crisis

3 Bartomeus, I. ${ }^{*}$, Stavert, J.R. ${ }^{2}$, Ward, D. ${ }^{2,3}$, and Aguado, 0.4

$5{ }^{1}$ Estación Biológica de Doñana (EBD-CSIC), Avda. Américo Vespucio 26, Isla de la Cartuja,

6 E-41092 Sevilla, Spain

$7 \quad 2$ Centre for Biodiversity and Biosecurity, School of Biological Sciences, The University of

8 Auckland, Auckland, New Zealand

$9 \quad{ }^{3}$ Landcare Research, Auckland, New Zealand

$10 \quad{ }^{4}$ Andrena Iniciativas y Estudios Medio Ambientales, Valladolid, Spain

12 *Correspondence: nacho.bartomeus@gmail.com

13

14 Author contributions: IB wrote the initial draft. DW and OA provided data. IB and JS

15 analysed the data. All authors contributed to writing the manuscript.

16 Running head: Historic collections and pollinators 


\section{Abstract}

18 There is increasing concern about the decline of pollinators worldwide. However, despite

19 reports that pollinator declines are widespread, data are scarce and often geographically

20 and taxonomically biased. These biases limit robust inference about any potential

21 pollinator crisis. Non-structured and opportunistic historical specimen collection data

22 provide the only source of historical information which can serve as a baseline for

23 identifying pollinator declines. Specimens historically collected and preserved in museums

24 not only provide information on where and when species were collected, but also contain

25 other ecological information such as species interactions and morphological traits. Here,

26 we provide a synthesis of how researchers have used historical data to identify long-term

27 changes in biodiversity, species abundances, morphology and pollination services. Despite

28 recent advances, we show that information on the status and trends of most pollinators is

29 absent, but we highlight opportunities and limitations to progress the assessment of

30 pollinator declines globally. Finally, we demonstrate different approaches to analysing

31 museum collection data using two contrasting case studies from distinct geographical

32 regions (New Zealand and Spain) for which long-term pollinator declines have never been

33 assessed. There is immense potential for museum specimens to play a central role in

34 assessing the extent of the global pollination crisis.

35 Keywords: Museums, biodiversity, global change, bees, hoverflies, butterflies. 


\section{Introduction}

37 Animal pollinators are a critical component of both natural and agricultural ecosystems

38 worldwide, given their role in plant reproduction [1] and food security [2]. As with many

39 other taxa, pollinators are vulnerable to a range of anthropogenic disturbances, which can

40 cause local and regional population declines or even extinctions. The vulnerability of

41 pollinators was identified several decades ago, and was popularized in 1996 by the

42 influential book "The forgotten pollinators" [3]. However, early accounts of pollinator

43 declines were somewhat anecdotal, given the lack of pollinator population data at that

44 time. These initial claims triggered the first efforts to assess this potential issue and

45 included the formation of a US National Academy of Science (NAS) panel in 2006, which

46 was commissioned to assess the extent of pollinator declines. The NAS report concluded

47 that "For most pollinator species [...] the paucity of long-term population data and the

48 incomplete knowledge of even basic taxonomy and ecology make definitive assessment of

49 status exceedingly difficult" [4]. Since then, studies on pollinator responses to various

50 global change drivers have multiplied rapidly. Researchers have now developed strong

51 consensus that disturbances such as habitat destruction, land-use intensification, chemical

52 exposure, exotic species and climate change are causing pollinator declines, and often act

53 synergistically $[5,6]$. Yet, the current status and population trends of most pollinator

54 species worldwide remain unknown. For example, a recent IUCN report concluded that

55 even for Europe's comparatively well-studied bee fauna, greater than $55 \%$ of bee species

56 fell into the "Data Deficient" category [7]. For countries outside of Europe and the US, data

57 on pollinator populations is almost non-existent. 
58 One of the main barriers to identifying long-term pollinator population trends is that

59 pollinators are incredibly taxonomically diverse and include bees, flies, butterflies, beetles,

60 birds, bats and lizards [8]. Additionally, many pollinators are highly mobile, short-lived and

61 small, which makes monitoring their populations difficult. Bees are generally regarded as

62 the most important pollinator group due to their abundance, pollination efficiency and

63 widespread distribution [9]. However, bees are diverse, with more than 20,000 species

64 currently described worldwide, and often require expert taxonomists for identification.

65 Furthermore, the uneven distribution of researchers has resulted in geographical biases in

66 bee decline research [10], as well as taxonomic biases toward species that are easier to

67 identify, such as bumblebees $[11,12]$.

68 One solution to overcoming these barriers is the use of space-for-time substitutions, where

69 researchers compare pollinator populations across environmental gradients. Despite

70 critiques on the robustness of this approach $[13,14]$, these studies currently provide the

71 most extensive source of pollinator population data. For example, researchers have

72 recently estimated bee richness declines for every country in Europe using predictions

73 from models of pollinator associations with different land-use types [15]. A second

74 important method is the use of data collected from pollinator monitoring programs, which

75 are often driven by citizen scientists. This approach was inspired by successful butterfly

76 monitoring programs [16] and is currently being extended to other pollinator taxa.

77 However, these programs require significant time to generate long-term datasets and

78 cannot be used to assess historic pollinator populations. Finally, the most practical

79 approach for assessing long-term historical pollinator population trends is to use historical 
80 information on species occurrences, which is often archived in museum collections [e.g.

81 17].

82 In this review, we first assess current evidence for pollinator richness declines and present

83 a roadmap outlining a strategy for using historical collection data to fill current knowledge

84 gaps. We highlight the major technical difficulties involved in using historical collection

85 data and demonstrate several approaches for analysing different types of collection data to

86 assess long-term pollinator population trends. Finally, we highlight the need to move

87 beyond simple biological diversity descriptors and unleash the power of historical data to

88 assess changes in species interactions, ecosystem functioning and evolutionary changes

89 through time.

\section{Current evidence on pollinator declines}

91 At a global scale, current evidence of pollinator declines is highly limited with most data

92 restricted to the US and Europe. It is unsurprising that studies on pollinator declines are

93 biased towards developed western countries, which have also been subject to extensive

94 anthropogenic disturbance. For example, in the UK and the Netherlands, a citizen science

95 based study using both observations and museum collection data detected strong richness

96 declines for bees, hoverflies and flowering plants [18]. In the Netherlands, museum data

97 have also revealed simultaneous plant and pollinator declines [19]. Specifically, bee species

98 with the strongest host plant preferences (i.e., specialists) displayed the strongest declines

99 and thus, were most threatened with extinction. However, it is important to note that even

100 for these two countries, local estimates of pollinator richness are biased toward large cities 
101 and regions dominated by agriculture, and thus lack data for well-preserved natural areas.

102 Further exploration of this dataset revealed that for declining pollinator taxa, the trend has

103 attenuated in recent decades [20].

104 Although studies of local pollinator communities often detect richness declines, regional

105 richness may remain relatively stable. For example, regional estimates for bee species

106 richness changes in the eastern US show moderate declines [17] and very few regional

107 extinctions [21]. This is a pattern also detected in the UK, where relatively few regional bee

108 extinctions have been reported [22]. These regional findings are in stark contrast with the

109 widespread local extinctions reported in local studies. For example, Burkle et al. [23]

110 compared historical observations of bee species' occurrences in a large forested ecosystem

111 with remaining forest remnants and reports several local extinctions. However, it is

112 important to note that there is strong concordance between local extinctions and regional

113 declines [24], suggesting that local extinctions are indicators of regional population

114 declines.

115 Reported declines for bumblebees are the most severe of all pollinator taxa. For example,

116 declines of up to $18 \%$ in local bumblebee richness have been reported for Belgium and the

117 Netherlands [20]. In other parts of Europe, local richness declines range from 5\% in Great

118 Britain [20] to $42 \%$ in Denmark [25]. In the USA, reported bumble decline are also severe

119 with estimates ranging between 25\% [26] and 30\% [17]. However, studies on species

120 richness changes for other pollinator taxa are both scarce and geographically restricted.

121 For butterflies, the only evidence of richness declines comes from Europe. Butterfly species

122 richness has declined substantially in the Netherlands and Belgium since the 1950's, 
123 although declines in Great Britain have been less severe [20]. In Belgium, another study

124 [27] found that richness declines have been severe (approximately 30\%), although this

125 study assessed richness changes over a longer time period (early 1900's to 2000)

126 compared to [20] (1950-69 vs. 1970-80 and 1970-89 vs. 1990-2009). In parts of Germany,

127 up to 70\% declines in local butterfly richness have been reported [28]. Compared with

128 other insect pollinator taxa, there are very few studies on hoverfly species richness

129 changes, which are all restricted to Europe. In Belgium, Great Britain and the Netherlands,

130 hoverfly richness changes have been modest [20]. In the Netherlands, moderate increases

131 in hoverfly species richness have been shown, whereas in Great Britain no significant

132 directional changes were detected [18]. Furthermore, directionality (richness increase or

133 decrease) varies depending on the time period assessed. For example, hoverfly richness

134 decreased in Belgium by approximately 6\% from 1950-69 to 1970-80, but increased by

135 approximately 10\% between 1970-89 and 1990-2009 [20].

136 For illustrative purposes, we mapped the findings of this studies in Figure 1 to show the

137 strong contrast between bee species richness worldwide, with bee diversity hotspots in

138 Mediterranean countries, against the paucity of countries for which we have any local or

139 regional data on bee, hoverfly or butterfly declines (see raw data in Sup Mat 1). Despite

140 outside of Europe and the US and for non-insect taxa, there are very few or no studies on

141 pollinator declines using historical records, there are species-specific examples of historical

142 losses from different parts of the world (e.g., Bombus dalbhomi; [29]). 


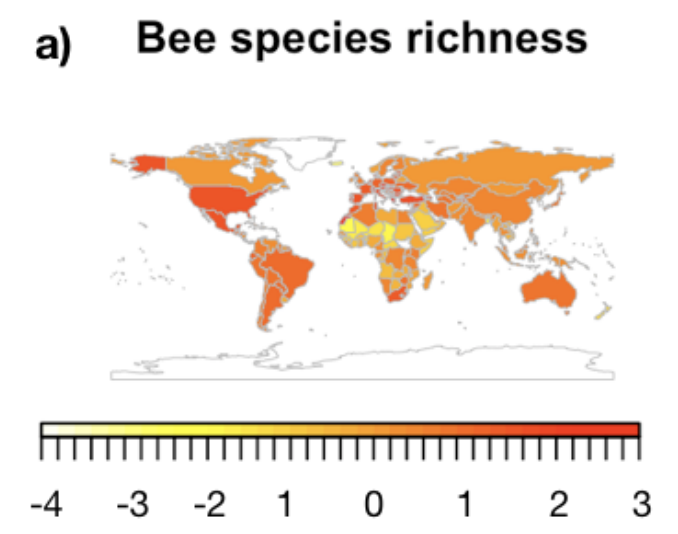

c) Average syrphid richness change 149 Countries with available historical changes in (b) bee, (c) hoverfly and (d) butterfly

150 richness within the last 100 years. Warmer colours indicate steeper average declines.

151 Countries without data are coloured in white. b) Average bee richness change

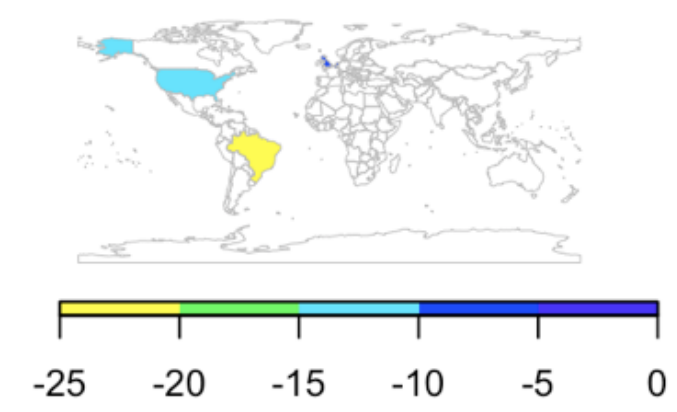

d) Average butterfly richness change

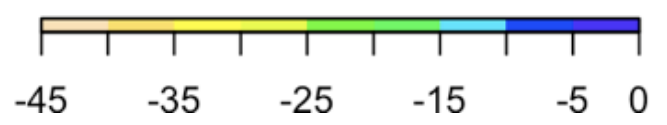

Figure 1: Global map showing a) bee species richness per area (Data from

www.discoverlife.org) calculated as the residuals of the log-log regression between bee species richness per country and country size. This correction accounts for the species-area relationship. Warmer colours indicate higher bee diversity. Note that some African countries may have incomplete listed faunas and that Alaska is included with USA values. 


\section{2 \\ Using historical collection specimen records to fill knowledge gaps}

153 Estimates of pollinator declines are lacking for most countries worldwide (Figure 1). The

154 use of historic collection data may be the most effective tool for filling these gaps. The core

155 aim of museums is to conserve and curate historic collections. Thus, they serve as a

156 precious repository for specimens, and at the same time, often ensure higher quality

157 taxonomic identification. Yet, the major bottleneck for researchers wanting to use these

158 data is the lack of digitization. Digitizing old collection specimens is not a trivial task and

159 requires expertise to (i) ensure proper taxonomic identification [30-32], (ii) geo-locate the

160 coordinates of collection events (e.g. http://www.geonames.org) and (iii) store the data in

161 a properly curated database [33]. Undertaking this process for tens or hundreds of

162 thousands of museum collection specimens can be a daunting task and requires specialized

163 personnel. While some tasks can only be undertaken by people with specialist skills (e.g.,

164 taxonomists), new technologies and citizen science can speed up the collection digitization

165 process. High resolution photos of specimens and associated labels can be uploaded to the

166 internet, where the task of image transcription can be distributed across hundreds or

167 thousands of volunteers (e.g., https://www.zooniverse.org/). In addition, new algorithms

168 have been created that allow location geo-referencing based on vernacular names (e.g.

169 https://geoparser.io). However, achieving this requires adequate funding [34].

170 Where digitization has been completed, the data provide a rich source of information,

171 allowing assessment of the current status and long-term trends of pollinator populations

$172[17,19,35]$. This is despite the fact that museum collections often have a number of biases,

173 including unknown sampling effort, personal interests of collectors and the curatorial 
174 techniques used. For example, collectors tend to target rare or unusual over common taxa,

175 discard damaged individuals or only accession a certain number of individuals. In addition,

176 collections are often made opportunistically, leading to a spatial biases where difficult to

177 access areas are under-sampled or conversely, where samples are biased towards easily

178 accessed locations (e.g., towns/cities and/or roadsides). Further, museum collection data

179 can only be used to determine where species are present and not where they are absent.

180 However, given adequate sample sizes and appropriate statistical techniques, most biases

181 can be accounted for [e.g. 17,36,37].

182 The way forward: Prioritizing the low hanging fruit.

183 As we have shown, there is a paucity of countries for which historical data is available

184 (Figure 1), and hence can be used as baseline for assessing pollinator population declines.

185 While ideally one would aim to digitize all museum collection records, this is unlikely in the

186 near future, predominantly due to funding constraints. Here we show how researchers can

187 optimize the use of historical collection data to assess long-term pollinator population

188 changes.

189 GBIF (https://www.gbif.org/) is a central repository for global species occurrence data.

190 Much of these data come from museums, private collections and government research

191 institutes, but several other sources are also integrated. In combination with the popular

192 statistical language R [38], GBIF can be directly queried into your computer [39] and data

193 availability can be checked for the region of interest. Focusing on bee taxa, we show here

194 the number of modern and historic bee records currently available for different countries 
195 (Figure 2a, Sup mat 2). Thirty-seven countries have more than 1800 records in each time 196 period, making these data potentially analyzable without further data collection effort (see

197 Figure $2 \mathrm{~b}$ and $\mathrm{c}$ for an initial exploration). However, a proper analysis of this dataset would 198 require a careful inspection of the data, as we detail below for two specific countries (Spain 199 and New Zealand). In contrast, most countries fall short in one or both axes of Figure 2a. 200 For example, a variety of countries located in different continents such as Switzerland, Sri

201 Lanka, Nicaragua or Zimbabwe have a decent number of recent records, but lack historical

202 collections. In this cases, researchers should prioritize the digitalization of old material

203 before embarking on data analyses. For this end, it is also important to note that historical

204 records are not always vouchered in local museums (i.e., many European and USA

205 museums contain large collections of pollinators from other countries). Finally, it's

206 remarkable that more than 192 countries have less than 1000 records for each of both time

207 periods, making them poor candidates for analysing long-term pollinator population

208 trends. Aside from bees, similar exploratory analyses can easily be conducted for other

209 taxa. 
a)

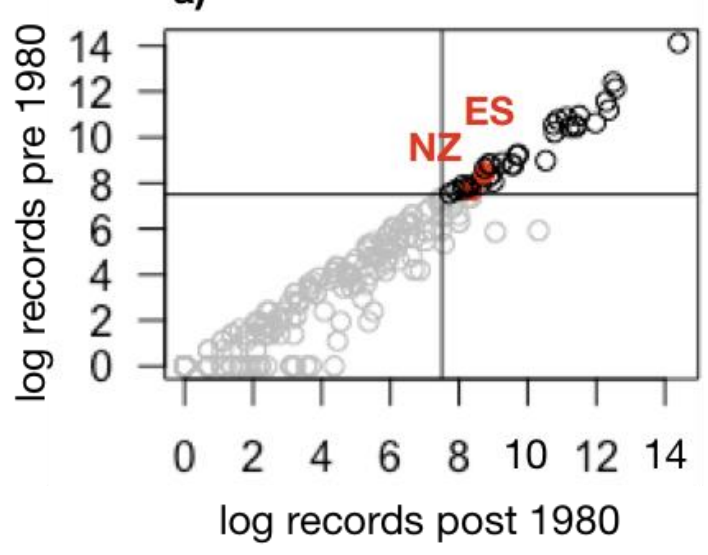

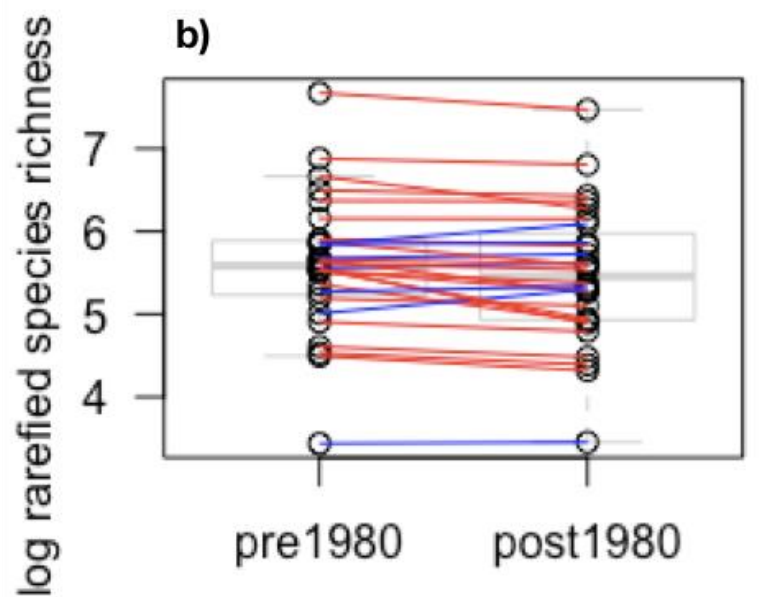

c)

Average bee richness change (\%)

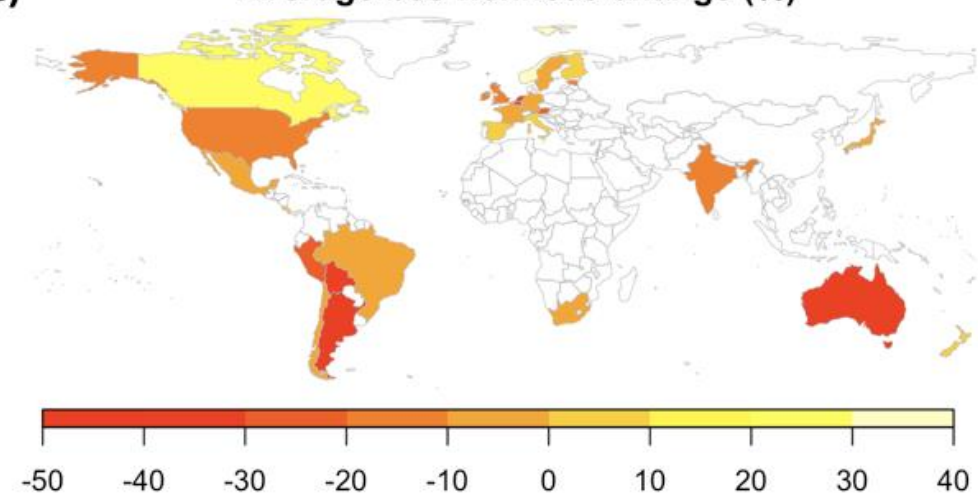

213 Figure 2. Exploration of available data for bee records showing: (a) The number of bee

214 occurrences before 1980 and after 1980 in GBIF for each country. The upper right quadrat

215 (records in black) contains well covered countries with New Zealand (NZ) and Spain (ES)

216 marked in red (see below). For well covered countries, we show preliminary comparisons

217 of the rarefied number of species in both time periods and show that for most countries (21

218 out of 28) the number of species recorded is slightly lower (average of $10 \%$ richness

219 decline; red lines) for recent time periods (b). Data is log transformed for visualization

220 purposes. A more careful analysis of this data would help complete the map of global

221 declines (c). In this map we plot the \% change in species recorded in GFIF for the available 
222 countries to show the potential geographic coverage. Note that this data is likely to contain

223 strong undetected biases, as we explore below.

224 As stated above, once historical collection datasets are made available, researchers must

225 identify any potential biases. We explore this process with two contrasting dataset

226 examples (Spain and New Zealand). In the Spanish dataset, most of the data comes from a

227 few specific locations and was collected by a few specific teams. Hence, the geographical

228 coverage is not representative. Even worst, historical and modern collections do not

229 overlap spatially, making any inference impossible to interpret. In this case, we contacted

230 the original collectors of the historical data to define their sampling protocols. We then

231 resurveyed the same sites (35 years after the original surveys) using the same sampling

232 protocols. In contrast, the New Zealand dataset includes a wide suite of collectors and

233 collection locations but shows no obvious biases in geographical and taxonomic coverage

234 through time. We complemented GBIF data with further museum collections for bees and

235 flies and analyze the regional richness changes through time. For these two case studies,

236 we provide annotated R scripts as examples of analysis for different dataset types (Sup Mat

237 3). These different analytical approaches allow us to reveal long-term trends in pollinator

238 populations for regions with contrasting sampling histories. We hope this resource will

239 encourage researchers to analyse data for regions where current information on pollinator

240 declines is lacking. 


\section{Case study one: Spain}

242 Spain provides an interesting study system because its natural habitats have been

243 transformed extensively by humans over a long time period, but land-use is not as

244 intensive compared with many other European countries. In addition, Spain is a bee

245 diversity hotspot (Figure 1a) and maintains a relatively heterogeneous landscape. Spain

246 has already digitalized a large amount of pollinator occurrence data for both historic and

247 recent periods (Figure 2a). However, visual inspection of the data revealed clustering

248 around a few localities. Further, historic records did not spatially match recent records,

249 making comparisons difficult. For this dataset, most of the historic records were located

250 around Valladolid and were collected by Enrique Asensio and collaborators. There has

251 been no recent sampling of bees in this area. However, we found that Enrique

252 systematically sampled six independent locations and that additional historical data were

253 available at the "Museo Nacional de Ciencias Naturales" and other minor collections.

254 Digitization of these records, along with a re-survey of the original sampling locations

255 provided an excellent dataset for a before and after comparison of bee communities.

256 In brief, after cleaning taxonomic names for possible typos and synonyms using the taxize

257 package [40], we checked for sampling completeness for both time periods and compared

258 rarefied species richness for each site before and after 1980 with a paired t-test

259 (rarefication at 1000 specimens). We found that there were a reduced number of species at

260 sites after 1980 (mean difference 20.27 species; 95 percent confidence interval: -1.03,

$26141.58 ; \mathrm{t}=2.44, \mathrm{df}=5, \mathrm{P}=0.06)$. However, this trend was highly dependent on site identity,

262 as two out of six sites showed no richness declines. Interestingly, these two localities were 
263 the two that has experienced less land use changes (both are natural areas embedded into

264 agro-ecosystems). In contrast the other 4 localities suffered large urban or agricultural

265 intensification. In addition, species lost in the re-surveys are not a random selection of

266 species, but are clustered in a few genera. For example, Andrenidae and their parasites (e.g.

267 Nomada) showed the strongest declines whereas Halictidae tend to be more stable (Sup

268 mat 4). This pattern of winners and losers of land use intensification is in accordance with

269 findings elsewhere [17], indicating that some clades are more sensitive to disturbance than

270 others.

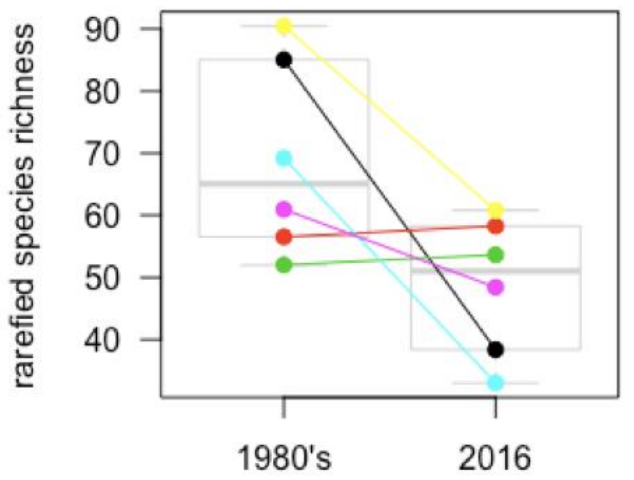

272 Figure 3. Comparison of historic collections (1980's) and modern re-surveys (2016) of the

273 rarefied richness of bees at six Spanish localities.

\section{Case study two: New Zealand}

275 In contrast to Spain, New Zealand is an isolated oceanic archipelago, with a distinctive

276 pollinator biota and a unique history of human occupation. Much of New Zealand's 
277 pollinator fauna is also relatively depauperate. For example, New Zealand has only 27

278 native bee species [41], which is a fraction of nearby Australia's c. 1600 species [42].

279 However, New Zealand has a surprisingly high diversity of flies (Diptera), which are

280 important pollinators in many ecosystems [43]. Thus, New Zealand provides a unique

281 system to study long-term changes in pollinator communities, and is unlike continental

282 Europe and the US, which have been the focus of an overwhelming majority of pollinator

283 decline studies.

284 In global terms, human colonisation of New Zealand was relatively recent (c. 740 y) [44].

285 Before human arrival, New Zealand was predominately forested, but has since been

286 dramatically altered by people. Early Māori settlers cleared forests by burning and more

287 recently, European colonists cleared large tracts of remaining forests and drained low-lying

288 wetlands for agriculture, mostly before 1900 [45]. Therefore, human activity likely affected

289 pollinator communities in New Zealand long before surveys and specimen collections

290 began. Nevertheless, we can use museum records to identify trends in pollinator

291 communities during New Zealand's more recent history.

292 We used New Zealand bee collection records gathered from multiple sources, including

293 university, research institute, museum and private collections. Collection records from the

294 New Zealand Arthropod Collection (NZAC) are freely available online

295 (https://scd.landcareresearch.co.nz/). Fly pollinator data was obtained from three

296 participating New Zealand museums and covers two families (Calliphoridae and Syrphidae)

297 that contain important fly pollinators. Collections for the bee and fly datasets span over 100

298 years (early 1900s to late 2000s). 
299 We followed protocols outlined in [17] to analyse the New Zealand data at the regional

300 level. First, we filtered our original datasets so that data used for analyses only included

301 independent collection events. To do this, we removed specimens collected at the same

302 location, on the same date, and by the same collector. We found our data had reasonable

303 coverage across time periods, although there was a peak in collection occurrences from

304 1960-1980. Further exploration of the New Zealand native bee data raised doubts on

305 collection completeness in records prior to 1970 , so we removed these records from

306 further analyses. We accounted for differences in collection effort through binning

307 collection records by time so that each bin had a similar number of records but a different

308 number of years. We then estimated richness for each time period bin by rarefying all bins

309 to an equal number of specimens and calculated the mean species richness \pm SE for each

310 bin. Finally, we estimated the significance of change in richness using a permutation test

311 that randomly reordered time periods and calculated the correlation between time period

312 and species richness. Thus, reported P-values were the proportion of permutations that

313 had higher or lower correlations compared to the correlation between richness and the

314 actual chronological time period sequence.

315 Second, to determine if the probability of finding a species in the collection changed over

316 time, we used a general linear model with a binomial distribution and a logit link. For

317 species that showed overdispersion, we used a quasi-binomial distribution. Further, we

318 only included species in this analysis for which we had 30 or more records. To account for

319 differences in sampling effort between years, we weighted each year by the total number of

320 samples collected that year. 
321 We found that rarefied richness for native bees was stable through time. Exotic bees

322 showed an increase in rarefied richness, but this trend was non-significant (P-value for

323 both natives and exotic bees $>0.05$ ). In contrast, native fly richness declined, whereas

324 exotic fly richness increased, although results for these groups were also non-significant

325 (P-values for both groups $>0.05$ ). Note that rarefied richness is sensitive to species

326 evenness, so increases in rarefied richness over time may actually indicate increased

327 species evenness and vice-versa for decreased richness.
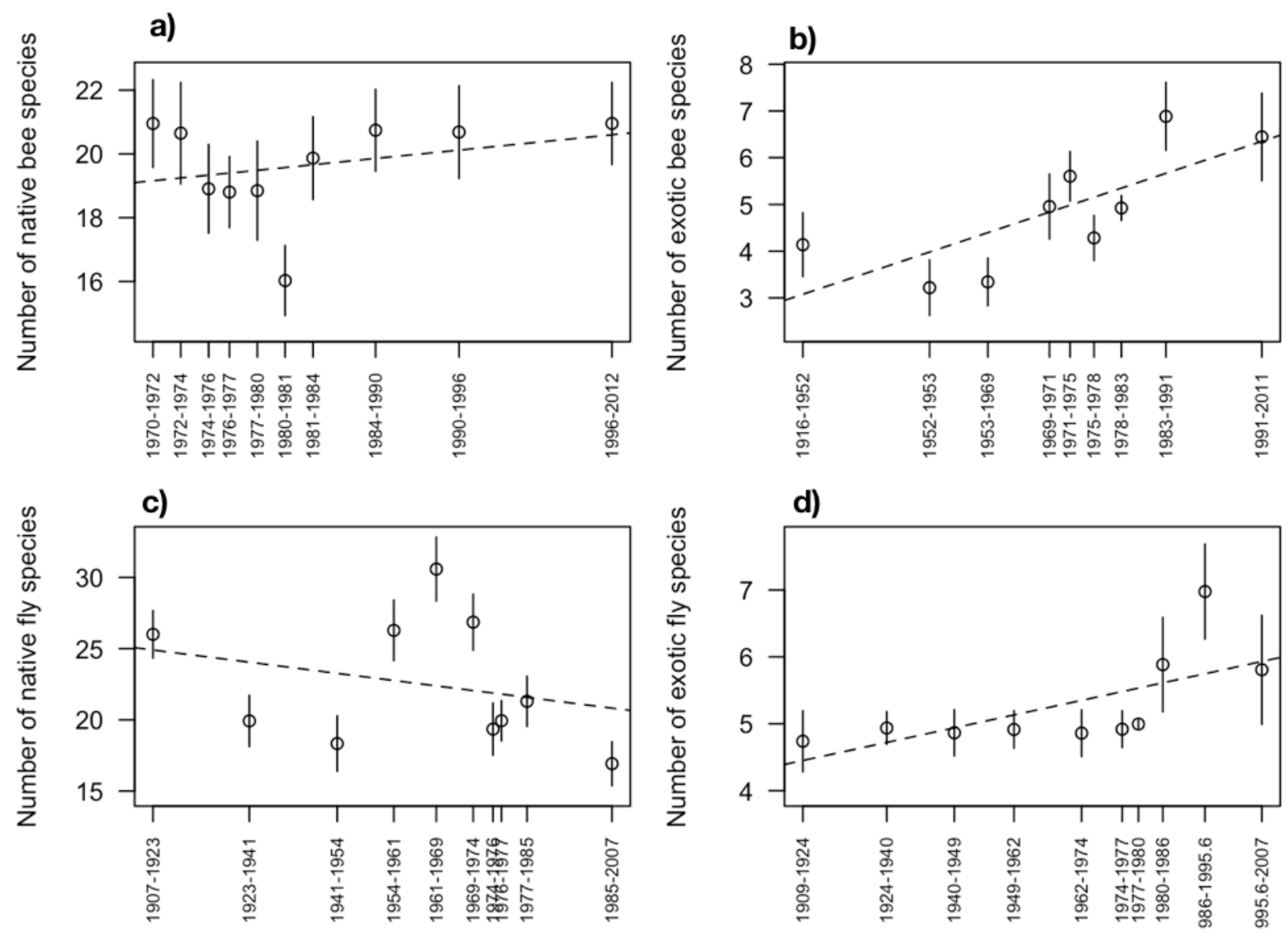

329 Figure 4. Changes in rarefied species richness for different pollinator groups in New

330 Zealand over time. All trends were non-significant $(\alpha=0.05)$. 
331 However, at the species level, we found that 11 out of 27 bee species increased in relative

332 occurrence over time (10 native and one exotic) and three bee species declined in relative

333 occurrence (one native and two exotic) (Figure 3). Interestingly, the two exotic bee species

334 that declined in relative occurrence were both in the genus Bombus, which were

335 intentionally introduced into New Zealand for the pollination of crops. Native bees that

336 increased in relative occurrence were mostly from the genus Leioproctus, which are

337 medium sized, ground nesting solitary bees. Only one out of 14 fly species increased in

338 relative occurrence, which was exotic, whereas four species decreased in occurrence (three

339 native and one exotic). Native flies that decreased in relative occurrence were all Syrphidae

340 in the genus Helophilus.

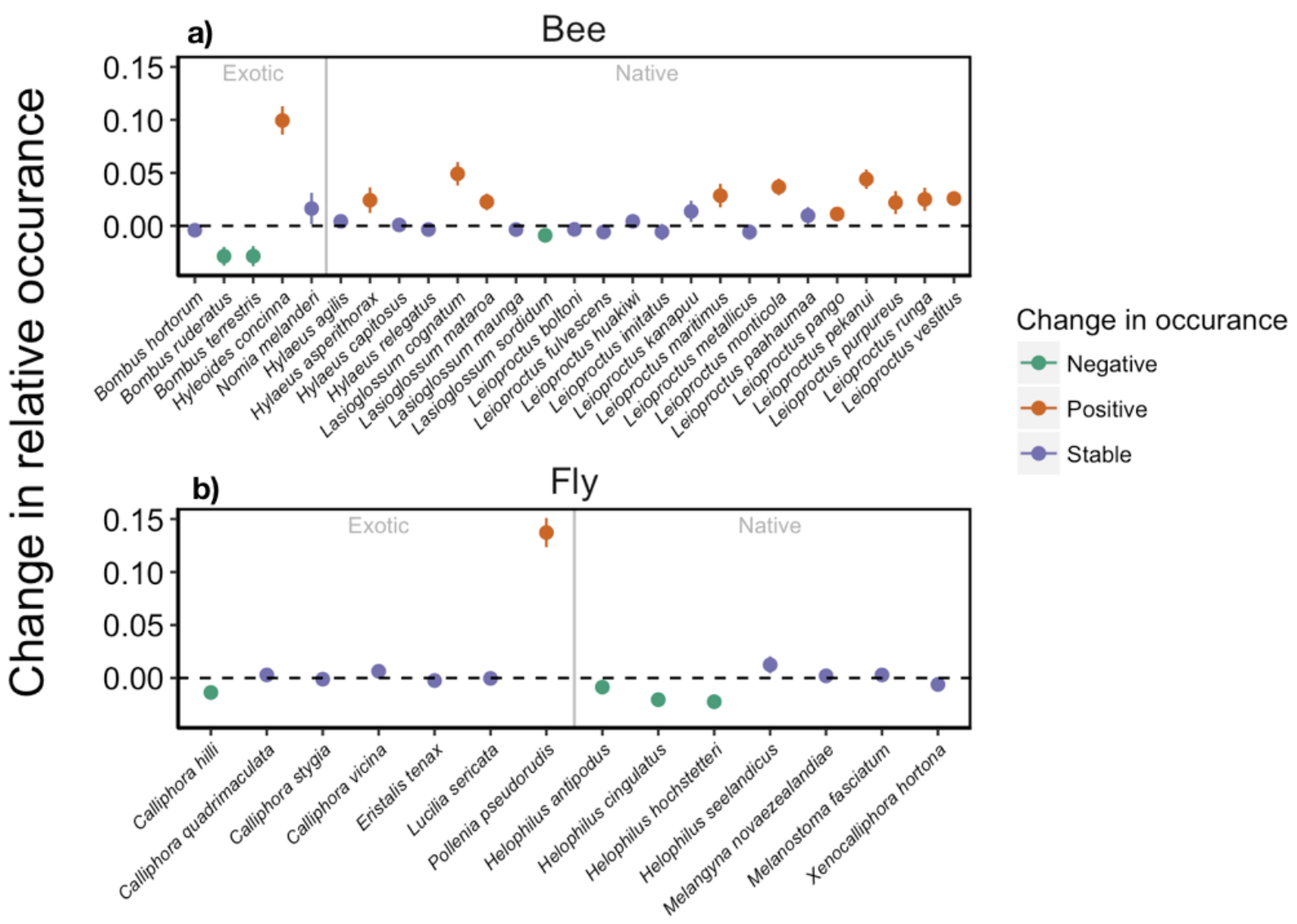


342 Figure 5. Model estimated changes $( \pm 1 \mathrm{SE})$ in the relative occurrence frequency of

343 different New Zealand bee and fly species in museum collections over time.

\section{Beyond species occurrences}

345 A recent study found that more than $90 \%$ of the papers investigating pollinator responses

346 to land-use change focused solely on richness and abundance descriptors [9]. But in

347 addition to local (alpha) diversity and regional (gamma) diversity, researchers need to

348 assess changes in turnover between sites (beta diversity). Environmental changes often

349 result in a few "winner" species and many "losers" species [17]. Identifying winners and

350 losers is critical as the few winners are often exotic and represent a subset of traits that

351 facilitate survival in highly modified environments [46]. These changes can have important

352 effects for pollination of native plant species and crops [47].

353 In addition, museum specimen collections can provide much more information besides

354 species occurrence records, given that such information is recorded when digitizing

355 collections. This is particularly important for identifying mechanisms of decline and

356 adaptation. For example, recording the date of collection is particularly important for

357 tracking of phenological advances congruent with contemporary climate change [48]. In

358 addition, pollinator specimen labels often include information about the host plant on

359 which the specimen was collected. This information critical for understanding past and

360 present species interactions [49]. Aside from this information, bee specimens often contain

361 pollen loads trapped on hairs, from which past visitation events can be identified [50].

362 Finally, museum specimens can be measured to track evolutionary changes by measuring 
363 the traits of specimen. This approach has been already used to investigate tongue length

364 [51] and body size [52] changes in response to climate and land-use change. Finally, plant

365 herbariums can also contain indirect evidence of pollinator and pollination declines [53], a

366 basic information for linking pollinator declines with its consequences for ecosystem

367 functioning.

\section{Conclusions}

369 Unleashing the power of museum collection data to answer pressing ecological and

370 evolutionary questions is at our hands, but requires the coordinated effort of many actors.

371 Using two case studies, we show that strong collaboration between museum curators and

372 ecologists is key to understanding data and treating it appropriately. To progress our

373 understanding of the global pollination crisis, researchers and curators must aim to digitize

374 museum collection data and make it readily available in a format that is widely accessible.

375 Centralization of regional and national museum collection data in existing global platforms,

376 such as GBIF, would facilitate free and widespread access. However, datasets could also be

377 stored in alternative webpages or database repositories (e.g., university and museum

378 webpages or Dryad) providing they are thoroughly documented and easily retrieved and

379 combined with other datasets using open science tools [54].

380 We must revolutionize the way that researchers collaborate with museums, in order to

381 foster healthy bidirectional relationships. For example, ecological researchers collect

382 massive amounts of specimens, but these are often inappropriately vouchered $[55,56]$,

383 rendering them less useful for future research. To improve this process, strong 
384 communication between museums and researchers is required. However, this can only be

385 achieved with adequate funding and recognition that accurate data recording and long-

386 term preservation are critical for research [57].

387 To identify global trends in pollinator declines we require robust data, collected from

388 diverse geographic regions. It is also crucial that these data are analysed appropriately.

389 This requires researches to identify biases and to any fill taxonomic and geographic gaps

390 where possible. We need to place increased emphasis on quantifying pollinator declines in

391 regions outside of the US and Europe, and for pollinator groups other than bees. For the US

392 and Europe, there have been few regional bee extinctions [17,22] but in disturbed

393 ecosystems, declines are widespread $[15,18]$. For most other pollinator taxa and regions

394 throughout the world we know almost nothing. Moving forward, the first step for many

395 taxa will be to identify and describe species. Only then can we begin to document pollinator

396 declines.

\section{Acknowledgements}

398 We thank Curro Molina, Carola Warner, Patrick McQuinn, and Crona McMonagle for data

399 entry and Gregorio Aguado for carrying out the Spanish re-sampling. We thank Barry

400 Donovan for providing New Zealand bee collection records and E. Asensio for sharing his

401 historical data and knowledge. We thank the "Museo Nacional de Ciencias Naturales",

402 specially Mercedes Paris, ITACyL (Instituto Tecnológico Agrario de Castilla y León),

403 Canterbury Museum, the New Zealand Arthropod Collection and the Museum of New

404 Zealand Te Papa Tongarewa for access to historical collections. IB was funded by a 
405 “Fundación Banco Bilbao Vizcaya Argentaria" (FBBVA) project. DW was funded through

406 Landcare Research within the Characterising New Zealand's Land Biota Portfolio.

407

408 The datasets supporting this article have been uploaded as part of the supplementary

409 material and will be deposited at dryad or Figshare upon acceptance.

410 We have no competing interests

411 References

412

413 1. Ollerton J, Winfree R, Tarrant S. 2011 How many flowering plants are pollinated by

414 animals? Oikos 120, 321-326.

415 2. Klein AM, Vaissiere BE, Cane JH, Steffan-Dewenter I, Cunningham SA, Kremen C,

416 Tscharntke T. 2007 Importance of pollinators in changing landscapes for world crops.

417 Proceedings of the Royal Society B: Biological Sciences 274, 303-313.

418 3. Buchmann SL, Nabhan GP. 1996 The forgotten pollinators.

419 4. National Research Council. 2007 Status of Pollinators in North America. Washington, DC:

420 The National Academies Press. (doi:doi:10.17226/11761)

421 5. Goulson D, Nicholls E, Botías C, Rotheray EL. 2015 Bee declines driven by combined

422 stress from parasites, pesticides, and lack of flowers. Science 347, 1255957. 
423 6. Potts SG, Biesmeijer JC, Kremen C, Neumann P, Schweiger O, Kunin WE. 2010 Global

424 pollinator declines: Trends, impacts and drivers. Trends in Ecology and Evolution 25, 345-

425353.

426 7. Nieto A et al. 2014 European red list of bees. Luxembourg: Publication Office of the

427 European Union 98.

428 8. Ollerton J. 2017 Pollinator Diversity: Distribution, Ecological Function, and Conservation.

429 Annual Review of Ecology, Evolution, and Systematics 48, 353-376. (doi:10.1146/annurev-

430 ecolsys-110316-022919)

431 9. Winfree R, Bartomeus I, Cariveau DP. 2011 Native pollinators in anthropogenic systems.

432 Annual Review of Ecology and Systematics 42, 1-21.

433 10. Martin LJ, Blossey B, Ellis E. 2012 Mapping where ecologists work: biases in the global

434 distribution of terrestrial ecological observations. Frontiers in Ecology and the Environment

435 10, 195-201. (doi:doi:10.1890/110154)

436 11. Archer CR, Pirk CWW, Carvalheiro LG, Nicolson SW. 2014 Economic and ecological

437 implications of geographic bias in pollinator ecology in the light of pollinator declines. Oikos

438 123, 401-407. (doi:doi:10.1111/j.1600-0706.2013.00949.x)

439 12. De Palma A et al. 2016 Predicting bee community responses to land-use changes:

440 Effects of geographic and taxonomic biases. Scientific Reports 6, 31153.

441 13. Franca F, Louzada J, Korasaki V, Griffiths H, Silveira JM, Barlow J. 2016 Do space-for-

442 time assessments underestimate the impacts of logging on tropical biodiversity? An

443 Amazonian case study using dung beetles. Journal of Applied Ecology 53, 1098-1105. 
444 14. De Palma A et al. 2018 Challenges With Inferring How Land-Use Affects Terrestrial

445 Biodiversity: Study Design, Time, Space and Synthesis. Next Generation Biomonitoring 58,

446163.

447 15. De Palma A, Kuhlmann M, Bugter R, Ferrier S, Hoskins AJ, Potts SG, Roberts SP,

448 Schweiger 0, Purvis A. 2017 Dimensions of biodiversity loss: Spatial mismatch in land-use

449 impacts on species, functional and phylogenetic diversity of European bees. Diversity and

$450 \quad$ Distributions 23, 1435-1446.

451 16. Swaay CA van, Nowicki P, Settele J, Strien AJ van. 2008 Butterfly monitoring in Europe:

452 methods, applications and perspectives. Biodiversity and Conservation 17, 3455-3469.

453 17. Bartomeus I, Ascher JS, Gibbs J, Danforth BN, Wagner DL, Hedtke SM, Winfree R. 2013

454 Historical changes in northeastern US bee pollinators related to shared ecological traits.

455 Proceedings of the National Academy of Sciences of the United States of America 110, 4656-

456 4660. (doi:10.1073/pnas.1218503110)

457 18. Biesmeijer JC et al. 2006 Parallel Declines in Pollinators and Insect-Pollinated Plants in 458 Britain and the Netherlands. Science 313, 351-354. (doi:10.1126/science.1127863)

459 19. Scheper J, Reemer M, Kats R van, Ozinga WA, Linden GT van der, Schaminée JH, Siepel H,

460 Kleijn D. 2014 Museum specimens reveal loss of pollen host plants as key factor driving

461 wild bee decline in The Netherlands. Proceedings of the National Academy of Sciences 111,

$462 \quad 17552-17557$. 
463 20. Carvalheiro LG et al. 2013 Species richness declines and biotic homogenisation have

464 slowed down for NW-European pollinators and plants. Ecology Letters 16, 870-878.

465 (doi:10.1111/ele.12121)

466 21. Colla SR et al. 2012 Documenting Persistence of Most Eastern North American Bee

467 Species (Hymenoptera: Apoidea: Anthophila) to 19902009. Journal of the Kansas

468 Entomological Society 85, 14-22. (doi:10.2317/JKES110726.1)

469 22. Ollerton J, Erenler H, Edwards M, Crockett R. 2014 Extinctions of aculeate pollinators in

470 Britain and the role of large-scale agricultural changes. Science 346, 1360-1362.

471 23. Burkle LA, Marlin JC, Knight TM. 2013 Plant-Pollinator Interactions over 120 Years:

472 Loss of Species, Co-Occurrence, and Function. Science 339, 1611-1615.

473 (doi:10.1126/science.1232728)

474 24. Bartomeus I, Winfree R. 2013 Pollinator declines: reconciling scales and implications

475 for ecosystem services. F1000Research 2.

476 25. Dupont YL, Damgaard C, Simonsen V. 2011 Quantitative historical change in bumblebee

477 (Bombus spp.) assemblages of red clover fields. PLoS ONE 6.

478 (doi:10.1371/journal.pone.0025172)

479 26. Grixti JC, Wong LT, Cameron SA, Favret C. 2009 Decline of bumble bees (Bombus) in the

480 North American Midwest. Biological Conservation 142, 75-84.

481 (doi:10.1016/j.biocon.2008.09.027)

482 27. Maes D, Van Dyck H. 2001 Butterfly diversity loss in Flanders (north Belgium): Europe’s 483 worst case scenario? Biological conservation 99, 263-276. 
484 28. Wenzel M, Schmitt T, Weitzel M, Seitz A. 2006 The severe decline of butterflies on

485 western German calcareous grasslands during the last 30 years: A conservation problem.

486 Biological Conservation 128, 542-552. (doi:10.1016/j.biocon.2005.10.022)

487 29. Morales CL, Arbetman MP, Cameron SA, Aizen MA. 2013 Rapid ecological replacement

488 of a native bumble bee by invasive species. Frontiers in Ecology and the Environment 11,

$489529-534$.

490 30. Meier R, Dikow T. 2004 Significance of Specimen Databases from Taxonomic Revisions

491 for Estimating and Mapping the Global Species Diversity of Invertebrates and Repatriating

492 Reliable Specimen Data. Conservation Biology 18, 478-488. (doi:doi:10.1111/j.1523-

$493 \quad 1739.2004 .00233 . x$

494 31. Huber JT. 1998 The importance of voucher specimens, with practical guidelines for

495 preserving specimens of the major invertebrate phyla for identification. Journal of Natural

496 History 32, 367-385.

497 32. Thomson SA et al. 2018 Taxonomy based on science is necessary for global

498 conservation. PLoS biology 16, e2005075.

499 33. Hart EM et al. 2016 Ten simple rules for digital data storage. PLoS computational

500 biology 12, e1005097.

501 34. Wiggins GB, Marshall SA, Downes JA. 1991 Importance of research collections of

502 terrestrial arthropods. A brief prepared by the Biological Survey of Canada (Terrestrial

503 Arthropods). Bulletin of the Entomological society of Canada 23, 16. 
504 35. Young BE, Auer S, Ormes M, Rapacciuolo G, Schweitzer D, Sears N. 2017 Are pollinating

505 hawk moths declining in the Northeastern United States? An analysis of collection records.

$506 \quad$ PloS one 12, e0185683.

507 36. Keil P, Biesmeijer JC, Barendregt A, Reemer M, Kunin WE. 2011 Biodiversity change is

508 scale-dependent: an example from Dutch and UK hoverflies (Diptera, Syrphidae).

$509 \quad$ Ecography 34, 392-401.

510 37. Pearce JL, Boyce MS. 2006 Modelling distribution and abundance with presence-only

511 data. Journal of applied ecology 43, 405-412.

512 38. R Core Team. 2017 R: A language and environment for statistical computing. $\mathrm{R}$

513 Foundation for Statistical Computing, Vienna, Austria.

514 39. Chamberlain S, Ram K, Barve V, Mcglinn D. 2014 rgbif: Interface to the Global

$515 \quad$ Biodiversity Information Facility API. R package version 0.77.

516 40. Chamberlain S, Szoecs E, Foster Z, Arendsee Z. 2018 Package 'taxize'.

517 41. Donovan BJ. 2007 Apoidea (Insecta: Hymenoptera). Fauna of New Zealand 57, 295.

518 42. Ascher JS, Pickering J. 2015 Discover Life bee species guide and world checklist

519 (Hymenoptera: Apoidea: Anthophila).

520 43. Newstrom L, Robertson AW. 2005 Progress in understanding pollination systems in

521 New Zealand. New Zealand Journal of Botany 43, 1-59. 
522 44. Wilmshurst JM, Anderson AJ, Higham TF, Worthy TH. 2008 Dating the late prehistoric

523 dispersal of Polynesians to New Zealand using the commensal Pacific rat. Proceedings of the

524 National Academy of Sciences 105, 7676-7680.

525 45. Perry GL, Wilmshurst JM, McGlone MS. 2014 Ecology and long-term history of fire in

526 New Zealand. New Zealand Journal of Ecology, 157-176.

527 46. Stavert JR, Pattemore DE, Gaskett AC, Beggs JR, Bartomeus I. 2017 Exotic species

528 enhance response diversity to land-use change but modify functional composition.

529 Proceedings of the Royal Society B: Biological Sciences 284. (doi:20170788)

530 47. Stavert JR, Pattemore DE, Bartomeus I, Gaskett AC, Beggs JR. 2018 Exotic flies maintain

531 pollination services as native pollinators decline with agricultural expansion. Journal of

532 Applied Ecology

533 48. Bartomeus I, Ascher JS, Wagner D, Danforth BN, Colla S, Kornbluth S, Winfree R. 2011

534 Climate-associated phenological advances in bee pollinators and bee-pollinated plants.

535 Proceedings of the National Academy of Sciences of the United States of America 108, 20645-

53620649.

537 49. Tylianakis JM, Didham RK, Bascompte J, Wardle DA. 2008 Global change and species

538 interactions in terrestrial ecosystems. Ecology Letters 11, 1351-1363. (doi:10.1111/j.1461-

$539 \quad 0248.2008 .01250 . x)$

540 50. Kleijn D, Raemakers I. 2008 A retrospective analysis of pollen host plant use by stable

541 and declining bumble bee species. Ecology 89, 1811-1823. 
542 51. Miller-Struttmann NE et al. 2015 Functional mismatch in a bumble bee pollination

543 mutualism under climate change. Science 349, 1541-1544.

544 52. Oliveira MO, Freitas BM, Scheper J, Kleijn D. 2016 Size and sex-dependent shrinkage of

545 Dutch bees during one-and-a-half centuries of land-use change. PloS one 11, e0148983.

546 53. Pauw A, Hawkins JA. 2011 Reconstruction of historical pollination rates reveals linked

547 declines of pollinators and plants. Oikos 120, 344-349.

548 54. Dallas T. 2016 helminthR: an R interface to the London Natural History Museum's host-

549 parasite database. Ecography 39, 391-393.

550 55. Packer L, Monckton SK, Onuferko TM, Ferrari RR. 2018 Validating taxonomic

551 identifications in entomological research. Insect Conservation and Diversity 11, 1-12.

552 56. Wheeler TA. 2003 The Role of Voucher Specimens in Validating Faunistic and Ecological

553 Research: A Brief. Biological Survey of Canada (Terrestrial Arthropods).

554 57. Ward DF, Leschen RA, Buckley TR. 2015 More from ecologists to support natural

555 history museums. Trends in ecology \& evolution 30, 373-374. 